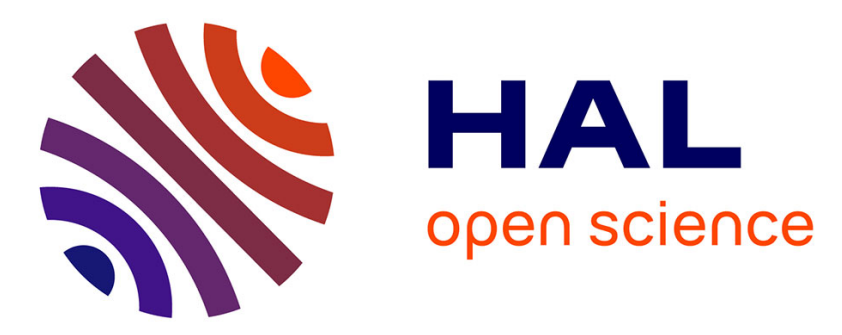

\title{
Examining smoking behaviours among parents from the UK Millennium Cohort Study after the smoke-free legislation in Scotland
}

\author{
Summer Sherburne Hawkins, Tim J Cole, Catherine Law
}

\section{- To cite this version:}

Summer Sherburne Hawkins, Tim J Cole, Catherine Law. Examining smoking behaviours among parents from the UK Millennium Cohort Study after the smoke-free legislation in Scotland. Tobacco Control, 2010, 20 (2), pp.112. 10.1136/tc.2010.037028 . hal-00585173

\section{HAL Id: hal-00585173 \\ https://hal.science/hal-00585173}

Submitted on 12 Apr 2011

HAL is a multi-disciplinary open access archive for the deposit and dissemination of scientific research documents, whether they are published or not. The documents may come from teaching and research institutions in France or abroad, or from public or private research centers.
L'archive ouverte pluridisciplinaire HAL, est destinée au dépôt et à la diffusion de documents scientifiques de niveau recherche, publiés ou non, émanant des établissements d'enseignement et de recherche français ou étrangers, des laboratoires publics ou privés. 


\section{Examining smoking behaviours among parents from the UK Millennium Cohort Study after the smoke-free legislation in Scotland}

Summer Sherburne Hawkins ${ }^{1}$, Tim J Cole ${ }^{2}$, Catherine Law ${ }^{2}$

Study design: Prospective nationally representative cohort study

Summer Sherburne Hawkins

Postdoctoral fellow

Tim J Cole

Professor

Catherine Law

Professor

${ }^{1}$ Harvard Center for Population and Development Studies, Harvard School of Public Health, 9 Bow Street, Cambridge, MA 02138 USA

${ }^{2}$ MRC Centre of Epidemiology for Child Health, UCL Institute of Child Health, 30 Guilford Street, London WC1N 1EH, UK

Please send all correspondence to: C Law

c.law@ich.ucl.ac.uk

Word count: 3769

Keywords: parents, smoking, preschool children, public policy 


\begin{abstract}
Objectives: To investigate parental smoking behaviours between England and Scotland after the smoke-free legislation in Scotland came into effect in 2006 and examine inequalities in maternal smoking behaviours between countries.

Methods: 5954 white mothers and 3757 fathers resident in England and 1522 white mothers and 904 fathers resident in Scotland who participated in the Millennium Cohort Study when the cohort child was age 9 months (before legislation) and 5 years (after legislation in Scotland but not in England). The main outcome measures were: smoking at 9 months and 5 years; quitting smoking by 5 years; starting smoking by 5 years.
\end{abstract}

Results: In England and Scotland approximately 30\% of parents reported smoking at 9 months with only a slight decrease in smoking at 5 years. There were no differences between countries in parental smoking after the smoke-free legislation in Scotland came into effect, taking into account prior smoking levels. Light smokers (1-9 cigarettes/day) from Scotland were less likely to quit by 5 years than those from England, but there were no differences between countries among heavy smokers (10+ cigarettes/day). Non-smoking mothers from Scotland (6.2\%) were less likely to start smoking by 5 years than mothers from England (7.3\%). Mothers from more disadvantaged circumstances in both countries were more likely to report that they smoked or started smoking. In England quitting was also socially patterned, but in Scotland, after the legislation was introduced, the gradients in quitting smoking were flatter across social groups. Conclusions: Smoking behaviours among parents with young children remained relatively stable, highlighting the need for additional tobacco control efforts to support smoking cessation. However, the smoke-free legislation does not appear to widen health inequalities and may even help reduce them by encouraging quitting across socioeconomic groups. 


\section{Introduction}

Despite the gradual reduction in smoking over recent decades in developed countries ${ }^{1}$, nearly one-third of British mothers continue to smoke before or during pregnancy ${ }^{2}$ and adults age 25-34 years have some of the highest levels of smoking ${ }^{3 ; 4}$. Infants' and children's principal exposure to environmental tobacco smoke (ETS) occurs in the home. ${ }^{5 ; 6}$ ETS related to parental smoking has been shown to increase the risk of low birth weight and sudden infant death syndrome as well as cause respiratory symptoms, asthma, and middle ear disease in children. ${ }^{5 ; 6}$ Adult smoking, including maternal smoking during pregnancy, is socially patterned ${ }^{2-4}$ and exposure to ETS is greater for children living in more disadvantaged households. ${ }^{6 ; 7}$

The aim of the legislation to prohibit smoking in enclosed spaces and workplaces has been to reduce ETS. ${ }^{8}$ Evaluations of smoke-free legislation in the UK and elsewhere have demonstrated a reduction in ETS among adults in the community and workplace, and primary schoolchildren. ${ }^{9-}$ ${ }^{12}$ There is also some evidence that the use of smoking cessation services has increased ${ }^{9 ; 12 ; 13}$ and smoking levels have decreased ${ }^{10 ; 14}$ since enactment of the legislation. Reductions in smoking among parents would benefit both them and their children; however, to our knowledge, the impact of smoke-free legislation on this group has not been examined.

Smoke-free legislation did not occur concurrently in the four countries of the UK. Legislation in Scotland came into effect on 26 March 2006, Wales on 2 April 2007, Northern Ireland on 30 April 2007, and England on 1 July 2007; thus, setting up a natural experiment which we were able to assess using data from the Millennium Cohort Study (MCS). ${ }^{8}$ The MCS is a prospective, nationally representative study of British children born at the start of the century and their parents. ${ }^{15}$ Contacts with the cohort have occurred when the children were age 9 months, 3 years, and 5 years. ${ }^{16}$ The MCS 5-year contact occurred after the legislation in Scotland came into effect but before the legislation in England, Wales, and Northern Ireland. Our aim was to investigate parental smoking behaviours and smoking in the home between England and Scotland from 9 months to 5 years. We also sought to examine inequalities in maternal smoking behaviours and smoking in the home between countries. 


\section{Methods}

\section{Participants}

Families were invited to participate in the MCS if they were resident in the UK when their child was age 9 months and eligible to receive Child Benefit (a universal benefit for families with children). ${ }^{15}$ The original cohort consisted of 18819 children (18 553 families) who were born between September 2000 and January 2002 (response 72\%). ${ }^{17}$ Of the 18296 singleton infants who participated in the first contact at 9 months, 79\% (14 403) participated in the third contact at 5 years. Interviews took place in the home with the main respondent (over 99\% were natural mothers at all contacts) and her partner (at the third contact, 94\% were natural fathers).

In this analysis we only included parents from England and Scotland because Northern Ireland and Wales had much smaller sample sizes than England. The third contact interviews occurred in England and Scotland between February 2006 and January 2007. While smoke-free legislation in Scotland came into effect on 26 March 2006, 99.6\% of families in Scotland had their third contact interview afterwards. All families in England were interviewed before the smoke-free legislation in England. Data were obtained from the UK Data Archive, University of Essex. The Millennium Cohort Study received ethical approval from the South West and London MultiCentre Research Ethics Committees. ${ }^{16}$

Of the 14403 singleton children and their families who participated in the first and third contacts, 10639 lived in either England or Scotland at both time points. The analyses were restricted to British/Irish white women (8346) because of ethnic differences in smoking. ${ }^{18}$ At the first contact mothers reported their ethnicity ${ }^{19}$ and white women were further categorised as being from the UK or Republic of Ireland (referred to as British/Irish) rather than any other European or other country ${ }^{20}$.

Among the 8346 British/Irish white mothers, 7476 were included in the analyses. Families were excluded if the main respondent was not female at either contact (139), the partner respondent was not male at the third contact (5), the main respondent was pregnant at the first (316) or third (405) contacts, or smoking information was missing at the first (7) or third (44) contacts. Some 
participants had more than one exclusion criterion. In the final sample, 5954 mothers were resident in England and 1522 in Scotland.

Paternal smoking behaviours were examined using a subset of the final sample which included 5718 families with two parents. Families were excluded if paternal smoking information was missing at the first (385), third (440), or both contacts (232). In the final sample (4661), 3757 fathers were resident in England and 904 in Scotland.

\section{Outcome measures}

At the first contact main and partner respondents were asked whether they currently smoked any tobacco products and, if so, the number of cigarettes or roll-ups they smoked a day. Mothers or fathers who smoked one cigarette per day or more were considered to be a smoker at 9 months. The latter two questions were asked again at the third contact (5 years). Moderate/heavy smoking (referred to as heavy) was defined as smoking 10 cigarettes or more daily. ${ }^{3 ; 4}$ Among parents who smoked at 9 months, those who reported not smoking any cigarettes at 5 years were considered to have quit smoking. Parents who were non-smokers at 9 months and reported smoking any cigarettes at 5 years were considered to have started smoking. For convenience smoking at each contact is defined in terms of the child's age, i.e. 9 months and 5 years. Thus 'smoking at 9 months' refers to adult smoking status when the child was 9 months old.

An indicator of smoking in the home was based on a question asked to main respondents at the first and third contacts: "Does anyone smoke in the same room as [^Cohort child] nowadays?" (response: yes or no). For convenience this is reported as 'smoking in the home'. No information was collected specifically on children's smoke exposure outside the family home.

\section{Socio-demographic characteristics}

Socio-demographic characteristics of the mothers and fathers were self-reported at the first contact, unless otherwise specified. Mothers' and fathers' socioeconomic circumstances were categorised $^{21}$ and collapsed into four groups. Mothers and fathers reported their age on leaving full-time education and age at the birth of the cohort child. Mothers also reported the number of children in the household. At the first contact mothers reported the household income; if missing, 
values from the second (328) or third (87) contacts were substituted. A variable called 'lone mother \& partner smoking status' was derived from a combination of lone parent status and partner smoking status at the first contact. At the third contact, maternal employment status was derived from mothers' report of her current employment status and, if working, the number of hours she worked per week. Since $94 \%$ of fathers were employed at the third contact, paternal employment status was included as employed yes/no.

\section{Statistical analyses}

We analysed parental smoking behaviours between countries through a logistic regression model of smoking at 5 years conditional on smoking at 9 months, with country included as a covariate and England as the baseline category. An odds ratio above/below one indicated a higher/lower odds of smoking in Scotland than in England. Mothers' regression analyses were adjusted for: maternal socioeconomic circumstances, age at leaving education, age at MCS birth, employment status, household income, number of children in the household, and lone mother \& partner smoking status. Fathers' analyses were adjusted for comparable variables. The same analytic approach was used to examine smoking in the home between countries; analyses were also adjusted for the number of cigarettes smoked at 9 months.

Logistic regression analyses were conducted to examine differences between countries in parental quitting (among smokers overall and stratified by light/heavy smoking) or starting smoking (among non-smokers) by 5 years. An odds ratio above/below one indicated a higher/lower odds of quitting or starting smoking in Scotland than in England. Analyses were adjusted for the socio-demographic characteristics listed previously. Quitting smoking was also adjusted for the number of cigarettes smoked at 9 months; however, the stratified analyses were not.

We examined separately the differences in socio-demographic characteristics between mothers from England and Scotland who at 5 years: smoked, quit smoking (among smokers), started smoking (among non-smokers), and reported smoking in the home. Unadjusted analyses were conducted, separately, for each outcome measure with an interaction between each socio- 
demographic characteristic and country. An adjusted Wald test evaluated whether differences between countries were statistically significant.

Analyses were conducted using STATA statistical software, version 10.1 SE (Stata Corporation, Texas) with survey commands to account for the clustered sampling design and obtain robust standard errors. Weighted percentages were derived and regression analyses were conducted using survey and non-response weights to account for the study design and attrition between contacts. Characteristics of parents from England and Scotland were compared using Pearson's $\chi^{2}$ tests.

\section{Results}

There were no significant differences between mothers from England and Scotland in socioeconomic circumstances, age at leaving education, employment status, age at the birth of the cohort child, or lone mother \& partner smoking status (all p>.05). Overall, 32\% of mothers held managerial or professional occupations, $49 \%$ left education at age 16 or under, $13 \%$ were lone parents, $60 \%$ were employed, and the mean age at the cohort child's birth was 29 years (interquartile range, 25 to 33 years). While one-quarter of households had an annual income of $£ 33000$ or more, $50 \%$ of households in England had an annual income of $£ 22000$ or less compared to $56 \%$ in Scotland $(\mathrm{p}=.03)$.

\section{a) Parental smoking at 9 months and 5 years by country (Table 1)}

In England and Scotland approximately 30\% of mothers reported smoking at 9 months and at 5 years. For fathers, around $30 \%$ reported smoking at 9 months decreasing to $25 \%$ at 5 years.

There were no significant differences between countries in parental smoking at 5 years, taking into account smoking levels at 9 months, before or after adjustment for socio-demographic characteristics. 
Table 1. Prevalence of parental smoking at 9 months and 5 years by country and odds of smoking at 5 years in Scotland compared to England

\begin{tabular}{|c|c|c|}
\hline & 9 months & 5 years \\
\hline \multicolumn{3}{|l|}{ Mothers } \\
\hline England (N=5954): Weighted \% (95\% CI) & $29.8 \%(28.1$ to 31.5$)$ & $27.7 \%(26.1$ to 29.4$)$ \\
\hline Scotland $(\mathrm{N}=1522)$ : Weighted $\%(95 \% \mathrm{CI})$ & $31.0 \%(27.9$ to 34.3$)$ & $30.3 \%(27.3$ to 33.5$)$ \\
\hline \multicolumn{3}{|l|}{$\begin{array}{l}\text { Odds ratio }(95 \% \mathrm{CI}) \text { of smoking at } 5 \text { years adjusted for } \\
\text { smoking at } 9 \text { months: }\end{array}$} \\
\hline Scotland compared to England & \multicolumn{2}{|c|}{$1.19(0.99$ to 1.43$)$} \\
\hline Adjusted* odds ratio $(95 \% \mathrm{CI})$ of smoking at 5 years: & \multirow{2}{*}{\multicolumn{2}{|c|}{$1.15(0.95$ to 1.40$)$}} \\
\hline Scotland compared to England & & \\
\hline \multicolumn{3}{|l|}{ Fathers } \\
\hline England (N=3757): Weighted \% (95\% CI) & $29.5 \%(27.7$ to 31.4$)$ & $24.2 \%(22.5$ to 26.0$)$ \\
\hline Scotland (N=904): Weighted \% (95\% CI) & $31.5 \%(27.6$ to 35.8$)$ & $27.5 \%(23.9$ to 31.5$)$ \\
\hline \multicolumn{3}{|l|}{$\begin{array}{l}\text { Odds ratio }(95 \% \mathrm{CI}) \text { of smoking at } 5 \text { years adjusted for } \\
\text { smoking at } 9 \text { months: }\end{array}$} \\
\hline Scotland compared to England & \multicolumn{2}{|c|}{1.25 (0.96 to 1.62$)$} \\
\hline Adjusted $\dagger$ odds ratio $(95 \% \mathrm{CI})$ of smoking at 5 years: & \\
\hline Scotland compared to England & \multicolumn{2}{|c|}{$1.24(0.95$ to 1.61$)$} \\
\hline
\end{tabular}

* Adjusted for maternal smoking at 9 months and maternal socioeconomic circumstances, maternal age at leaving education, maternal age at MCS birth, household income, number of children in the household, maternal employment status, lone mother \& partner smoking status $\dagger$ Adjusted for paternal smoking at 9 months and paternal socioeconomic circumstances, paternal age at leaving education, paternal age at MCS birth, household income, number of children in the household, paternal employment status, maternal smoking status at 9 months

\section{b) Parents who quit smoking by $\mathbf{5}$ years (among smokers) by country (Table 2)}

Mothers and fathers from Scotland were less likely to quit by 5 years than parents from England, before or after adjustment (columns A). Stratifying by the number of cigarettes smoked revealed that light smokers from Scotland were less likely to quit by 5 years than light smokers from England (columns B), while there were no differences in quitting among heavy smokers (columns C). 
Table 2. Prevalence of parents who quit smoking by 5 years among (a) all smokers, (b) light smokers, and (c) heavy smokers by country and odds of quitting smoking in Scotland compared to England

\begin{tabular}{|c|c|c|c|c|c|c|}
\hline & & Mothers & & & Fathers & \\
\hline & $\begin{array}{c}\text { All smokers } \\
\text { England } N=1796 \\
\text { Scotland } N=450 \\
\text { A }\end{array}$ & $\begin{array}{c}\text { Light smokers } \\
\text { (1-9 cigarettes) } \\
\text { England } N=654 \\
\text { Scotland } N=139 \\
B\end{array}$ & $\begin{array}{c}\text { Heavy smokers } \\
(10+\text { cigarettes }) \\
\text { England } N=1142 \\
\text { Scotland } N=311 \\
C\end{array}$ & $\begin{array}{c}\text { All smokers } \\
\text { England } N=1133 \\
\text { Scotland } N=272 \\
\text { A }\end{array}$ & $\begin{array}{c}\text { Light smokers } \\
\text { (1-9 cigarettes) } \\
\text { England } N=303 \\
\text { Scotland } N=58 \\
\text { B }\end{array}$ & $\begin{array}{c}\text { Heavy smokers } \\
(10+\text { cigarettes }) \\
\text { England } N=830 \\
\text { Scotland } N=214 \\
C\end{array}$ \\
\hline England: Weighted \% (95\% CI) & $24.0 \%(21.7$ to 26.5$)$ & $37.8 \%(33.6$ to 42.2$)$ & $16.0 \%(13.9$ to 18.4$)$ & $28.8 \%(26.0$ to 31.7$)$ & $44.8 \%(38.5$ to 51.3$)$ & $22.7 \%(19.8$ to 25.9$)$ \\
\hline Scotland: Weighted $\%(95 \% \mathrm{CI})$ & $16.0 \%(12.7$ to 19.9$)$ & $24.6 \%(18.1$ to 32.6$)$ & $12.2 \%(9.2$ to 16.0$)$ & $20.5 \%(16.1$ to 25.7$)$ & $22.6 \%(13.7$ to 35.0$)$ & $19.9 \%(14.9$ to 26.2$)$ \\
\hline $\begin{array}{l}\chi^{2} ; \mathrm{p} \text { value } \\
\text { Unadjusted odds ratio }(95 \% \mathrm{CI}) \text { : }\end{array}$ & $12 ; \mathrm{p}<.001$ & $8 ; p=.005$ & $3 ; p=.08$ & $7 ; p=.007$ & $10 ; \mathrm{p}=.002$ & $0.7 ; p=.4$ \\
\hline $\begin{array}{l}\text { Scotland compared to England } \\
\text { Adjusted odds ratio }(95 \% \mathrm{CI}) \text { : }\end{array}$ & $0.60(0.45$ to 0.81$)$ & $0.54(0.35$ to 0.83$)$ & $0.73(0.51$ to 1.04$)$ & $0.64(0.46$ to 0.89$)$ & $0.36(0.19$ to 0.70$)$ & $0.85(0.57$ to 1.26$)$ \\
\hline Scotland compared to England & $0.65(0.47$ to 0.89$) * \dagger$ & $0.54(0.33$ to 0.87$) *$ & $0.71(0.50$ to 1.03$) *$ & $0.66(0.46$ to 0.93$) \ddagger \S$ & $0.35(0.19$ to 0.67$) \ddagger$ & $0.83(0.56$ to 1.24$) \ddagger$ \\
\hline
\end{tabular}

* Adjusted for: maternal socioeconomic circumstances, maternal age at leaving education, maternal age at MCS birth, household

income, number of children in the household, maternal employment status, lone mother \& partner smoking status

$\dagger$ Adjusted for number of cigarettes mothers smoked at 9 months

\$ Adjusted for: paternal socioeconomic circumstances, paternal age at leaving education, paternal age at MCS birth, household

income, number of children in the household, paternal employment status, maternal smoking status at 9 months

$\S$ Adjusted for number of cigarettes fathers smoked at 9 months 


\section{c) Parents who started smoking by 5 years (among non-smokers) by country (Table 3)}

There were no differences between countries in mothers who started smoking by 5 years.

However, after adjustment, non-smoking mothers from Scotland were less likely to start smoking by 5 years than mothers from England. Among fathers, there were no differences between countries in starting to smoke before or after adjustment.

Table 3. Prevalence of parents who started smoking by 5 years (among non-smokers at 9 months) by country and odds of starting smoking in Scotland compared to England

\begin{tabular}{lc|c}
\hline & Mothers & Fathers \\
\hline & $\begin{array}{c}\text { England N=4158 } \\
\text { Scotland N=1072 }\end{array}$ & $\begin{array}{c}\text { England N=2624 } \\
\text { Scotland N=632 }\end{array}$ \\
\hline England: Weighted \% $(95 \% \mathrm{CI})$ & $7.3 \%(6.5$ to 8.1$)$ & $4.5 \%(3.7$ to 5.5$)$ \\
$\begin{array}{l}\text { Scotland: Weighted \% }(95 \% \mathrm{CI}) \\
\chi^{2} ; \mathrm{p} \text { value }\end{array}$ & $6.2 \%(4.9$ to 7.8$)$ & $3.6 \%(2.3$ to 5.7$)$ \\
$\begin{array}{l}\text { Unadjusted odds ratio }(95 \% \mathrm{CI}): \\
\text { Scotland compared to England }\end{array}$ & $2 ; \mathrm{p}=.2$ & $0.7 ; \mathrm{p}=.4$ \\
$\begin{array}{l}\text { Adjusted odds ratio }(95 \% \mathrm{CI}): \\
\text { Scotland compared to England }\end{array}$ & $0.84(0.64$ to 1.11$)$ & $0.80(0.48$ to 1.34$)$ \\
\hline
\end{tabular}

* Adjusted for: maternal socioeconomic circumstances, maternal age at leaving education, maternal age at MCS birth, household income, number of children in the household, maternal employment status, lone mother \& partner smoking status $\dagger$ Adjusted for: paternal socioeconomic circumstances, paternal age at leaving education, paternal age at MCS birth, household income, number of children in the household, paternal employment status, maternal smoking status at 9 months

\section{d) Smoking in the home at 9 months and 5 years by country (Table 4)}

Overall, approximately $15 \%$ of mothers reported that anyone smoked in the home. There were no significant differences between countries in smoking in the home at 5 years, taking into account levels at 9 months, before or after adjustment. 
Table 4. Prevalence of mothers reporting anyone smoked in the same room as the cohort child at 9 months and 5 years by country and odds of smoking in the same room at 5 years in Scotland compared to England

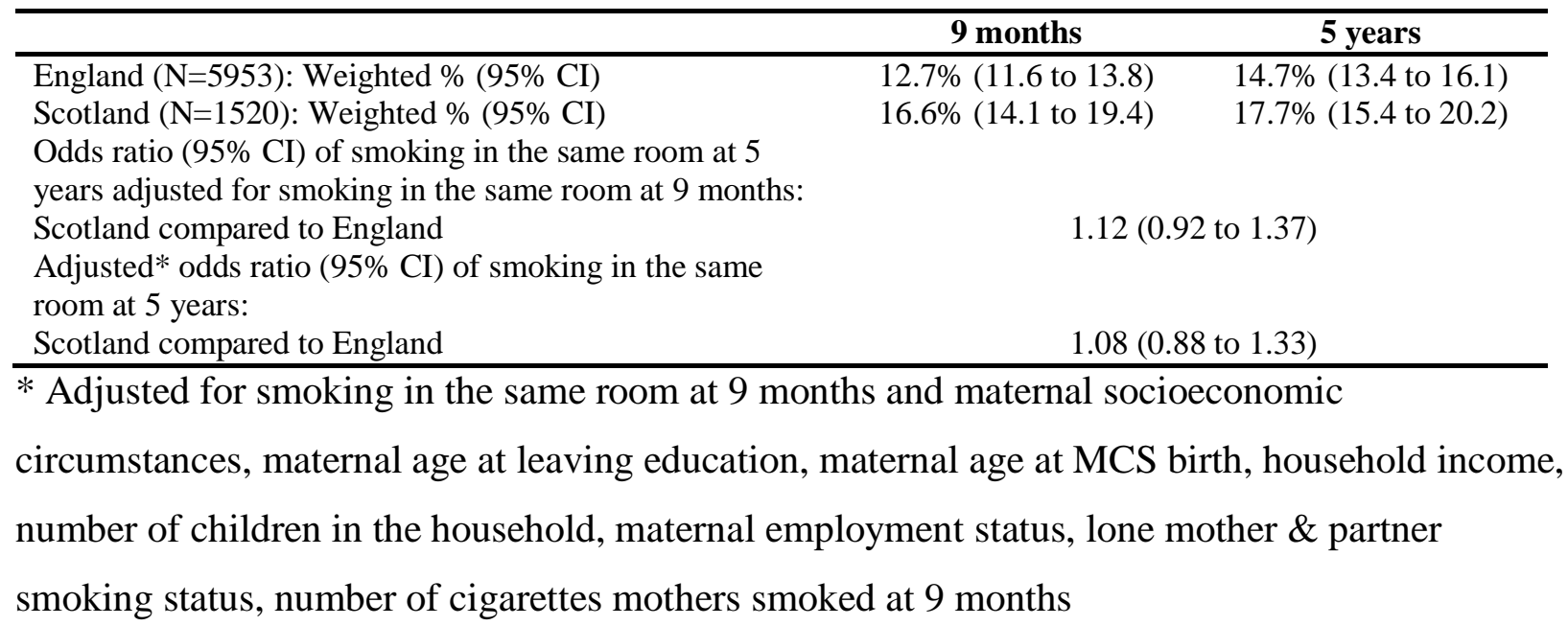

\section{e) Differences in socio-demographic characteristics between mothers from England and Scotland at 5 years (Table 5)}

There were marked gradients in smoking at 5 years in England and Scotland, with mothers from more disadvantaged circumstances more likely to smoke (columns A). For example, nearly $60 \%$ of mothers reported smoking who had never worked or were long-term unemployed, gave birth to the cohort child at age 19 or younger, or had a household income of $£ 11000$ or less. These patterns were consistent between countries (interactions $\mathrm{p}>0.05$ ).

Among smokers, the social patterning of quitting differed between England and Scotland (columns B). In England gradients were apparent for quitting for all socio-demographic characteristics, with mothers from more disadvantaged circumstances less likely to quit. In contrast, in Scotland gradients in quitting were much flatter.

The gradients for quitting by maternal socioeconomic circumstances $(\mathrm{p}=.002)$ and household income ( $\mathrm{p}=.04)$ were different between England and Scotland. In England, mothers in routine or manual occupations (OR $0.38,95 \%$ CI 0.28 to 0.52 ) or who had never worked or were long-term unemployed $(0.26,0.14$ to 0.47$)$ were less likely to quit than mothers in managerial or 
professional occupations. In Scotland, differences were only found for mothers who had never worked or were long-term unemployed (0.07, 0.01 to 0.52$)$. In England, mothers with a household income of $£ 11000-£ 22000$ (0.59, 0.41 to 0.84$)$ or $£ 11000$ or less $(0.36,0.25$ to 0.52$)$ were less likely to quit than mothers with a household income of $£ 33000+$. In contrast, there were no differences in quitting by household income in Scotland.

There were social gradients for both England and Scotland in mothers starting smoking by 5 years (columns C) and reporting smoking in the home (columns D). Mothers from more disadvantaged circumstances or who were younger at the birth of the cohort child were three times as likely to report that they started smoking or anyone smoked in the home as mothers from more advantaged circumstances or who were older. These patterns were consistent between countries for both factors (interactions $\mathrm{p}>0.05$ ). 
Table 5. Differences in socio-demographic characteristics between mothers from England and Scotland who at 5 years: (a) smoked;

(b) quit smoking (among smokers); (c) started smoking (among non-smokers); (d) reported smoking in the home

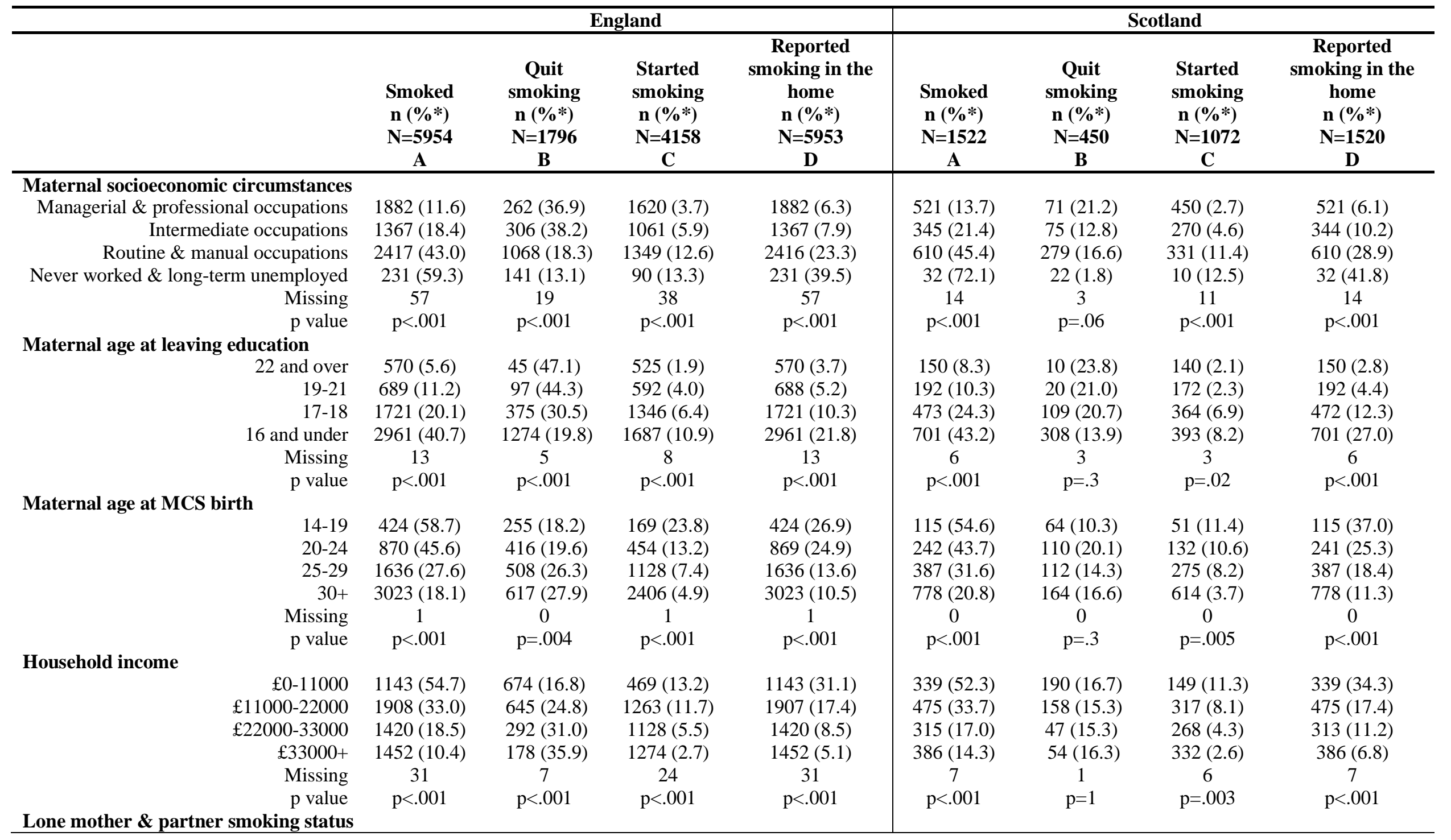




\begin{tabular}{|c|c|c|c|c|c|c|c|c|}
\hline Partner non-smoker & $3016(11.3)$ & $330(34.8)$ & $2686(4.8)$ & $3016(5.7)$ & $772(11.5)$ & $75(15.9)$ & $697(3.7)$ & $771(6.7)$ \\
\hline Partner smoker & $1556(45.1)$ & $795(22.7)$ & $761(11.6)$ & $1555(24.8)$ & $372(52.5)$ & $203(16.0)$ & $169(11.6)$ & $371(28.0)$ \\
\hline Partner unknown smoking status & $599(29.3)$ & $177(20.1)$ & $422(8.9)$ & $599(17.2)$ & $144(29.6)$ & $42(13.7)$ & $102(7.0)$ & $144(18.9)$ \\
\hline Lone parent & $783(56.4)$ & $494(20.4)$ & $289(16.6)$ & $783(27.7)$ & $234(52.3)$ & $130(16.7)$ & $104(12.0)$ & $234(33.4)$ \\
\hline Missing & 0 & 0 & 0 & 0 & 0 & 0 & 0 & 0 \\
\hline $\mathrm{p}$ value & $\mathrm{p}<.001$ & $\mathrm{p}<.001$ & $\mathrm{p}<.001$ & $\mathrm{p}<.001$ & $\mathrm{p}<.001$ & $p=1$ & $\mathrm{p}<.001$ & $\mathrm{p}<.001$ \\
\hline
\end{tabular}

* Weighted percentage 


\section{Discussion}

We examined differences between England and Scotland in parental smoking behaviours before and after the smoke-free legislation in Scotland. In both countries approximately 30\% of parents reported smoking at 9 months with only a slight decrease in smoking when their child was age 5 .

We found no differences between England and Scotland in parental smoking over the 10 month period that the smoke-free legislation in Scotland came into effect. Light smokers from Scotland were less likely than those from England to quit by 5 years, but there were no differences between countries in quitting among heavy smokers. Non-smoking mothers from Scotland (6.2\%) were less likely to start smoking by 5 years than mothers from England (7.3\%). We found no differences between countries in mothers reporting that anyone smoked in the same room as the cohort child. Our results suggest that smoking behaviours among parents with young children have remained relatively stable over time even after the smoke-free legislation in Scotland.

Mothers from more disadvantaged circumstances from both countries were more likely to report that they smoked, started smoking, or anyone smoked in the home at 5 years, after the smokefree legislation in Scotland came into effect. While quitting smoking was socially patterned in England, with mothers from more disadvantaged circumstances less likely to quit, flatter gradients were seen in Scotland.

\section{Strengths and limitations}

The timing of the MCS interviews in relation to the smoke-free legislation in Scotland provided a unique opportunity to examine smoking behaviours among parents with young children and health inequalities. Evaluations of natural experiments are often under-utilised, but can provide valuable insights into the impact of a policy on health and its inequalities, particularly for interventions that cannot be randomised. ${ }^{22}$

The MCS is a nationally representative, contemporary study of families providing a large sample of adults with detailed information on smoking behaviours and a range of socio-demographic factors. This allowed us to control for the individual characteristics of the mothers and fathers who lived in each country and reduce the potential for confounding. While the resulting 
differences in smoking behaviours may be attributed to the policies or programmes in each country rather than the social- and health-related profiles of the parents themselves, the possibility of residual confounding remains.

There are limitations to the MCS and its use in evaluating the smoke-free legislation. For $45 \%$ of the participants in Scotland the MCS interview took place within the first six months after the legislation, which may be too soon to impact smoking levels. However, there is also evidence for an increase in smoking cessation in the months leading up to the smoke-free legislation in Scotland. ${ }^{23}$ Smoking behaviour was collected by self-report at each contact and it may underestimate tobacco intake compared to biochemical measures, such as cotinine. ${ }^{24}$ There may also be cultural or other differences between countries related to smoking behaviours and/or smoking in the home. This includes the social desirability of reporting smoking around a child that may be affected by the smoke-free legislation. Unfortunately, we cannot account for this in the analyses. In the MCS there has been attrition between the first and third contacts and nonresponse weights were included in all analyses. Forty percent of British/Irish white mothers who participated in the first contact only ( $\mathrm{N}=2007)$ reported smoking at 9 months compared to 29\% who participated in the first and third contacts $(\mathrm{N}=8346)(\mathrm{p}<.001)$. However, we have no reason to believe that the smoking behaviours between countries would be different for those mothers who did not participate. The prevalence of smoking among mothers in the MCS was also similar to that reported for women from national health surveys in both countries. ${ }^{3: 4}$ Our analyses only included British/Irish white women and $97 \%$ of their partners were also British/Irish white, so results may not be applicable to parents from ethnic minority groups. Additional research is necessary to examine the impact of smoke-free legislation across ethnic groups.

While a benefit of the MCS is that fathers were interviewed at each contact, 2815 fathers were not included in our analyses because of missing data. The prevalence of paternal smoking in our study is lower than estimates from national health surveys ${ }^{3 ; 4}$, suggesting that our figures may under-estimate smoking among men. While there appears to have been a decline in smoking over time among fathers, the decrease in prevalence may be related to the sample and/or reporting bias. Further research using other samples would help to better understand these differences. 
Our analyses were limited to the questions asked of parents in the MCS interviews. Mothers reported whether anyone smoked in the same room as the cohort child, which should be considered only as an indicator of smoking in the family home because it is likely to underestimate ETS. Since the prevalence of reported smoking in the same room as the cohort child remained consistent over time, this provides little evidence to support the concern that smoking in the home may increase as a result of the legislation, which is similar to other studies. ${ }^{1125}$ Future research should also collect information on whether home smoking restrictions are present, as evidence suggests that smokers with home smoking bans increase quit attempts ${ }^{26}$ which could reduce children's exposure to ETS.

\section{Comparison with literature}

Evaluations of the smoke-free legislation in England and Scotland have found high levels of support by the public, increases in the use of smoking cessation services, and improvements in air quality. ${ }^{9 ; 12 ; 13}$ The first European countries to enact comprehensive legislation to prohibit smoking in enclosed spaces and workplaces were Ireland, Norway, and Italy. ${ }^{8}$ Decreases in the prevalence of smoking among adults have been found in all countries. ${ }^{14}$ However, none of these studies have specifically looked at the smoking habits of parents with young children. Not only did we find that light smokers from Scotland were less likely to quit by 5 years than those from England, but there were no differences in quitting among heavy smokers. These results suggest that the smoke-free legislation did not appear to influence smoking behaviour, particularly for heavy smokers. Cigarette consumption is one of the strongest predictors of smoking cessation ${ }^{27}$ and there were more parents from Scotland who reported being a heavy smoker. Among smokers in the MCS at 9 months, $70 \%$ of mothers and $79 \%$ of fathers from Scotland were heavy smokers compared to $63 \%$ and $73 \%$ from England, respectively. The MCS did not collect information on quit attempts or the reasons for parents quitting. Of particular concern is that approximately $7 \%$ of mothers started smoking by 5 years and half reported smoking 10 cigarettes or more daily (data not shown). Although this may, in part, be due to some misreporting of smoking at 9 months postpartum, it is not possible to determine. Discussions of smoking cessation are a priority for health professionals during pregnancy through early childhood ${ }^{28}$ and our results confirm the importance of promoting smoking cessation during well-child contacts until at least school-age. We found evidence that mothers from Scotland were less likely to take up smoking 
than mothers from England after enactment of the legislation and further research is necessary to better understand this relationship.

\section{Implications for practice and policy}

Reducing smoking among adults and mothers during pregnancy are priorities for Government. ${ }^{29-}$

${ }^{32}$ Addressing the gradients in smoking ${ }^{3 ; 4}$ is also pivotal to Government's strategy to reduce socioeconomic health inequalities. ${ }^{30 ; 32}$ Evaluations of the legislation have found reductions in ETS $^{9-12}$ and decreases in smoking levels ${ }^{10 ; 14}$; however, if changes occur primarily in more advantaged groups, then inequalities may widen. Despite the social patterning of smoking and ETS exposure, there is limited research examining the impact of tobacco control policies on health inequalities. This needs to be a critical component of formal evaluations. There is some evidence in Scotland that increases in smoking cessation immediately prior to the legislation were not related to socioeconomic status. ${ }^{23}$ Akhtar and colleagues found that secondhand smoke exposure in primary schoolchildren fell across social classes after the smoke-free legislation in Scotland, but cotinine levels remained highest for children from the most disadvantaged groups. ${ }^{33}$ We found that in Scotland, after the legislation came into effect, quitting smoking was similar across social groups, whether defined by occupation, education, or income; however, mothers from disadvantaged circumstances were still more likely to smoke, start smoking, or report smoking in the home. In contrast, gradients in England were seen for all smoking behaviours. The smoke-free legislation does not appear to widen health inequalities and may even help reduce them by encouraging quitting across socioeconomic circumstances. Studies examining these relationships in other adult populations with a larger sample size would help determine whether the legislation has been a useful intervention for improving health behaviours in more disadvantaged groups.

In the US at least one-third of children continue to be exposed to ETS in the home, with nearly half of children living in disadvantaged households likely to live with a smoker. ${ }^{7}$ Children's ETS exposure in the UK is likely to be similar. As we have shown, parents from disadvantaged circumstances are more likely to continue smoking, start smoking, and report smoking in the home. Our results suggest that health professionals should continue to play an active role in addressing maternal and paternal smoking behaviours throughout childhood. Smoke-free 
legislation is just one component of comprehensive tobacco control policies ${ }^{34 ; 35}$ to help create an environment that decreases the use of tobacco products, supports smoking cessation, and improves the health of adults and children. 


\section{What this paper adds}

- Previous research has shown that adult smoking is socially patterned and exposure to ETS is greater for children living in more disadvantaged households. Evaluations of smoke-free legislation have found reductions in ETS and decreases in smoking levels; however, the impact of smoke-free legislation on parents with young children has not been examined.

- In England and Scotland approximately 30\% of parents reported smoking at 9 months with only a slight decrease in levels by 5 years.

- There were no differences between countries in parental smoking over the period that the smoke-free legislation in Scotland came into effect; thus, highlighting the need for additional tobacco control efforts to support smoking cessation.

- In Scotland, after the legislation, the gradients in quitting smoking were flatter across social groups while in England quitting was socially patterned. The smoke-free legislation does not appear to widen health inequalities and may even help reduce them by encouraging quitting across socioeconomic groups. 


\section{Acknowledgments}

We would like to thank all of the Millennium Cohort Study families for their cooperation, and the Millennium Cohort Study team at the Centre for Longitudinal Studies, Institute of Education, University of London.

\section{Ethics approval}

The MCS received ethical approval from the South West and London Multi-Centre Research Ethics Committees; however, no additional ethics approval was required for this study.

\section{Funding details}

The Millennium Cohort Study is funded by grants to Professor Heather Joshi, director of the study from the ESRC and a consortium of government funders. Summer Sherburne Hawkins is a Robert Wood Johnson Foundation Health \& Society Scholar at the Harvard University site in Boston, Massachusetts. TJC is funded through an MRC programme grant (G0700961). Research at the Institute of Child Health and Great Ormond Street Hospital for Children NHS Trust benefits from R\&D funding received from the NHS Executive. The study design, collection, analysis, and interpretation of data, writing of the report, and the decision to submit the article for publication was conducted independent of the funding sources.

\section{Details of contributors}

SSH and CL contributed to the conception, study design, analysis, interpretation of the data, and drafted the article. TJC contributed to the analysis and interpretation of the data. All authors have also seen and approved the final version. CL will act as guarantor for the paper.

\section{Copyright}

The Corresponding Author has the right to grant on behalf of all authors and does grant on behalf of all authors, an exclusive licence (or non exclusive for government employees) on a worldwide basis to the BMJ Publishing Group Ltd, and its Licensees to permit this article (if accepted) to be published in Tobacco Control editions and any other BMJPGL products and to exploit all subsidiary rights, as set out in our licence (bmj.com/advice/copyright.shtml). 


\section{Competing interest statement}

All authors declare that the answer to the questions on your competing interest form are all No and therefore have nothing to declare. 


\section{References}

1 Guindon GE, Boisclair D. Past, current and future trends in tobacco use. http://www1.worldbank org/tobacco/pdf/Guindon-Past,\%20current-\%20whole.pdf (accessed 6 Aug 2009).

2 Bolling K, Grant C, Hamlyn B, Thornton A. Infant feeding survey 2005. London: The Information Centre for Health and Social Care, 2007.

3 Wardle H. Cigarette smoking. Health survey for England 2003 - volume 2. Norwich: The Stationery Office, 2004.

4 MacGregor A, Wardle H. Smoking. In: Bromley C, Sproston K, Shelton N, eds. The Scottish health survey 2003 - volume 2. Edinburgh: Scottish Executive, 2005.

5 Scientific Committee on Tobacco and Health (SCOTH), Department of Health. Secondhand smoke: review of evidence since 1998. London: Department of Health, 2004.

6 U.S. Department of Health and Human Services. The health consequences of involuntary exposure to tobacco smoke: a report of the surgeon general. Atlanta, GA: U.S.

Department of Health and Human Services, Centers for Disease Control and Prevention, Coordinating Center for Health Promotion, National Center for Chronic Disease Prevention and Health Promotion, Office on Smoking and Health, 2006.

$7 \quad$ King K, Martynenko M, Bergman MH, Liu Y-H, Winickoff P, Weitzman M. Family composition and children's exposure to adult smokers in their homes. Pediatrics 2009;123:e559-e64.

8 ASH Scotland. Smoke-free legislation around the world. http://www.ashscotland.org.uk/ash/4267 html (accessed 6 Aug 2009).

9 Donnelly P, Whittle P. After the smoke has cleared--reflections on Scotland's tobacco control legislation. Public Health 2008;122:762-6.

10 McNabola A, Gill LW. The control of environmental tobacco smoke: a policy review. Int J Environ Res Public Health 2009;6:741-58.

11 Akhtar PC, Currie DB, Currie CE, Haw SJ. Changes in child exposure to environmental tobacco smoke (CHETS) study after implementation of smoke-free legislation in Scotland: national cross sectional survey. BMJ 2007;335:545-9.

12 ASH Scotland. National evaluation of Scotland's smoke-free legislation. http://www.ashscotland.org.uk/ash/5510.html (accessed 7 Aug 2009). 
13 Department of Health. Smokefree England - one year on. London: Department of Health, 2008.

14 Gorini G, Constantini AS, Paci E. Smoking prevalence in Italy after the smoking ban: towards a comprehensive evaluation of tobacco control programs in Europe. Prev Med 2007; 45:123-4.

15 Dex S, Joshi H. Babies of the new millennium. London: Policy Press, 2005.

16 Hansen K. Millennium cohort study first, second, and third surveys: a guide to the datasets. London: Institute of Education, University of London, 2008.

17 Plewis I. Millennium cohort study: technical report on sampling 4th edition. London: Institute of Education, University of London, 2007.

18 Wardle H. Use of tobacco products. In: Sproston K, Mindell J, eds. Health survey for England 2004 - volume 1. The health of minority ethnic groups. Leeds: The Information Center, 2006.

19 Office for National Statistics. Ethnic group statistics: a guide for the collection and classification of ethnicity data. London: The Stationery Office, 2003.

20 Griffiths LJ, Tate AR, Dezateux C, The Millennium Cohort Study Child Health Group. The contribution of parental and community ethnicity to breastfeeding practices: evidence from the Millennium Cohort Study. Int J Epidemiol 2005;34:1378-86.

21 Rose D, Pevalin D. A researcher's guide to the national statistics socio-economic classification. London: Sage Publications, 2003.

22 Petticrew M, Cummins S, Ferrell C, Findlay A, Higgins C, Hoy C, et al. Natural experiments: an underused tool for public health? Public Health 2005;119:751-757.

23 Fowkes FJI, Stewart MCW, Fowkes GR, Amos A, Price JF. Scottish smoke-free legislation and trends in smoking cessation. Addiction 2008;103:1888-95.

24 Gorber SC, Schofield-Hurwitz S, Hardt J, Levasseur G, Tremblay M. The accuracy of self-reported smoking: a systematic review of the relationship between self-reported and cotinine-assessed smoking status. Nicotine Tob Res 2009;11:12-24.

25 Holliday JC, Moore GF, Moore LAR. Changes in child exposure to secondhand smoke after implementation of smoke-free legislation in Wales: a repeated cross-sectional study. BMC Public Health 2009;9:430. 
26 Mills AL, Messer K, Gilpin EA, Pierce JP. The effect of smoke-free homes on adult smoking behavior: a review. Nicotine Tob Res 2009;11:1131-41.

27 Hyland A, Li Q, Bauer JE, Giovino GA, Steger C, Cummings KM. Predictors of cessation in a cohort of current and former smokers followed for over 13 years. Nicotine Tob Res 2004; 6(suppl 3):S363-9.

28 Department of Health. Healthy child programme: pregnancy and the first five years of life. London: The Stationery Office, 2009.

29 Scottish Executive. A breath of fresh air for Scotland-improving Scotland's health: the challenge - tobacco control action plan. Edinburgh: Scottish Executive, 2004.

30 Department of Health. Tackling health inequalities: 2007 status report on the programme for action. London: Department of Health, 2008.

31 HM Government. PSA delivery agreement 18: promote better health and wellbeing for all. London: HM Treasury, 2009.

32 The Scottish Government. Equally well: report of the ministerial task force on health inequalities. Edinburgh: The Scottish Government, 2008.

33 Akhtar PC, Haw SJ, Levin KA, Currie DB, Zachary R, Currie CE. Socioeconomic differences in secondhand smoke exposure among children in Scotland after introduction of the smoke-free legislation. J Epidemiol Community Health 2010;64:341-6.

34 Department of Health. Tobacco. http://www.dh.gov.uk/en/Publichealth/Healthimprovement/Tobacco/index.htm (accessed 8 Aug 2009).

35 The Scottish Government. Tobacco. http://www.scotland.gov.uk/Topics/Health/health/Tobacco (accessed 8 Aug 2009). 